\title{
Internal Combustion Engines Water Injection fed by Exhaust Water Recirculation: a feasibility analysis
}

\author{
A. VAUDREY ${ }^{*}, 1,2$ \\ ${ }^{1}$ Univ. Lyon, ECAM Lyon, INSA-Lyon, LabECAM, F-69005, France. \\ ${ }^{2}$ Pontificia Universidad Católica del Peru (PUCP), Laboratorio de Energía, Lima, Peru.
}

February 13, 2018

\begin{abstract}
Water injection (WI) is one of the ways usable to mitigate the tail pipe pollution of internal combustion engine propelled vehicles. Despite its well-known good points, such a process may require the presence of an additional liquid water tank on board. In this paper, we assess the possibility to recycle some water vapour contained within the engine exhaust gas stream in order to supply WI and then reduce as far as possible the size of the water tank. The influence of parameters such as the ambient humidity, the fuel chemical composition, the Water-Fuel Ratio and the water recycling system effectiveness are taken into account. Obtained results are really encouraging: in considering the effectivenesses of existing water recycling membranes usable with exhaust gas streams, almost all water needs of WI processes could be satisfied, for both liquid (gasoline and Diesel) and gaseous fuels (hydrogen and natural gas). The Exhaust Water Recirculation system presented in this paper is thus probably one of the key components WI will need to be used more widely on actual vehicles.
\end{abstract}

Keywords : Water injection, Fogging, Exhaust Water Recirculation.

\section{Introduction}

Despite some recent and quite blaring announcements by politics, industrialists or journalists [1], of the coming end of Internal Combustion Engine (ICE) propelled vehicles era (supposedly replaced soon by electrical ones), their complete disappearance is probably not likely to happen any time soon. Such shift, when actually occurring, will be gradual, partly because of the time needed for dedicated industries and infrastructures to grow [2], but also because of the large financial capacity required from the whole society to invest in such new technologies $[3,4]$. We will thus certainly have to stand for ICE and its harmful polluting emissions during decades more. Decreasing these pollutions, including carbon dioxide, is then an immediate priority and must be achieved by any mean possible.

Different technologies can be used to decrease the amount of pollutants produced by ICE, and among them a specific one with a quite lively history: water injection (WI). Injecting liquid water into ICE is an idea as old as the ICE itself: some of the first gas engines developed near the mid XIX century, as the one of Hugon for example [5], used this process to "control" their combustion phenomena. Later, such a strategy has been used at different times and in different contexts, from the famous supercharged World War II aircraft engines [6] to the recent BMW M4 GTS model [7], through some Renault 1980s
F1 supercharged engines [8]. While all these applications of WI were dedicated to performance improvement - and can have, ceteris paribus, an indirect positive effect on the amount of fuel consumed, and then on the amount of pollutants rejected - the same process is also relevant to mitigate some polluting emissions, and first of all those of nitrogen oxides $\left(\mathrm{NO}_{x}\right)$.

Whatever it be, the use of WI on an ICE propelled vehicle requires to carry on board the sufficient amount of liquid water for so, in a supplementary water tank for instance. The aim of this paper is to assess the possibility to use, thanks to an Exhaust Water Recirculation (EWR) process, some liquid water extract by condensation from the ICE exhaust gas stream, in order to supply the WI system, and then to reduce the size of the concerned water tank. Whereas this idea has been already proposed in different patents [9-11], its feasibility has apparently not been yet analysed from a larger point of view, considering different consumed fuels or different ambient conditions.

After a short review of the known effects of WI on the performance and polluting emissions of ICE, a complete water balance of such an engine is presented. From that, a new criterion of WI self supplied operation is introduced. The influence on such a criterion of usual parameters as the Water-Fuel Ratio, the ambient humidity or the consumed fuel chemical composition, is detailed. Thanks to this analysis, we conclude that, considering the per-

\footnotetext{
${ }^{*}$ Corresponding author : alexandre.vaudrey@ecam.fr, ORCID iD: 0000-0002-8613-774X
} 
formance of already existing water recycling membranes, such a process can self supply engines WI systems in almost any situations, even within a very dry ambient air and whatever the fuel consumed, liquid or gaseous.

We are confident that such results are of a great interest for anyone interesting in implementing WI on vehicles, and we are quite surprised that such an idea has not been more widely tested so far.

\section{Effects of water injection on internal combustion engines}

\subsection{Effects on performance}

Liquid water can be practically injected either into the engine intake port, we then talk about port/indirect water injection (IWI), inlet manifold water injection or sometimes about intake fumigation $[12,13]$; or directly within the latter cylinder(s), via a direct water injection (DWI) strategy [14].

When IWI is used, the liquid water injected into the intake manifold evaporates and the enthalpy of vaporisation thus absorbed is removed from the enthalpy of the whole intake stream, and cools it down. The fresh mixture is subjected to a temperature drop and then to an increase of its density. The amount of fuel aspirated (for spark ignited engines) or directly injected into the engine cylinder (for compression ignited engines) is thus increased [15]. Power and efficiency increase whereas specific fuel consumption and specific production of carbon dioxide, per $\mathrm{kWh}$ produced, decrease.

IWI and DWI can also lead to a lower compression stroke required mechanical work, the gas to compress being initially at a lower temperature and some remaining liquid water being potentially vaporised during the compression in order to "internally" refrigerate it [16]. Both WI strategies decrease the combustion flame temperature, the fresh mixture being at lower temperature at the end of the compression stroke and the heat of combustion being released in a larger amount of gas. The probability of knock phenomena is thus reduced, and the fresh mixture octane number is increased [17, 18]. Higher compression ratios can then be reached. Finally, the amount of gas involved in the expansion stroke is increased and so the mechanical work provided by the latter.

\subsection{Effects on polluting emissions}

Considering engines polluting emissions, WI participates to decrease the amount of nitrogen oxides $\left(\mathrm{NO}_{x}\right)$ finally rejected by the combustion, in decreasing the flame temperature [19-24], the main source of $\mathrm{NO}_{x}$ being the oxidation process of atmospheric nitrogen contained in the air composing the fresh mixture, due to a too high combustion peak temperature [25]. On the contrary, the production of unburnt hydrocarbons increases, purportedly because of an enlargement of the quenching layers of combustion, due to the cooling process of the cylinder inner surface $[26,27]$. Finally, WI can whether decrease or increase the production of carbon monoxide (CO), depending on the specific experimented configuration [28].

\section{Internal combustion engines water balance}

\subsection{Ambient humidity}

The first amount of water, as vapour, which is always involved in the operation of ICE is the one naturally contained in the ambient air. Expressed as an aspirated mass flow rate, and noted $\dot{m}_{0}$, it can be written as the products:

$$
\dot{m}_{0}=\dot{m}_{\text {air }} \cdot \omega_{0}=\dot{m}_{\text {fuel }} \cdot \operatorname{AFR} \cdot \omega_{0}
$$

$\dot{m}_{\text {air }}$ and $\dot{m}_{\text {fuel }}$ are the mass flow rates of dry air and fuel, respectively, which are required by the engine combustion process. AFR is the Air-Fuel Ratio defined as:

$$
\mathrm{AFR}=\frac{\dot{m}_{\mathrm{air}}}{\dot{m}_{\mathrm{fuel}}}
$$

whom actual value depends on the fuel chemical composition and of the Air-Fuel equivalence Ratio, often noted $\lambda$ and defined as:

$$
\lambda=\frac{\mathrm{AFR}}{\mathrm{AFR}_{\mathrm{st}}}
$$

The subscript "st" means stoichiometric: $\lambda=1$ for a stoichiometric combustion, while $\lambda>1$ for a lean combustion, i.e. with excess air, and $\lambda<1$ for a rich combustion [25]. Values of $\mathrm{AFR}_{\mathrm{st}}$ corresponding to the fuels considered in this paper are presented in Table 1.

The last parameter involved in equation (1) is the specific humidity $\omega$ (sometimes called moisture content, humidity ratio or mixing ratio), defined as the ratio of the amount of water vapour (so the subscript "vap") mixed with ambient dry air, to the amount of the latter [30, chapter 6]:

$$
\omega=\frac{m_{\mathrm{vap}}}{m_{\mathrm{air}}}
$$

Such a parameter can be practically measured in the ambient air thanks to a common humidity sensor [30, chapter 14].

For a gasoline fed engine $\left(\mathrm{AFR}_{\mathrm{st}} \simeq 14.5\right)$ with a stoichiometric combustion $(\lambda=1)$ and an ambient air at temperature of $20^{\circ} \mathrm{C}$ and a relative humidity of $50 \%$, which corresponds to a specific humidity $\omega_{0} \simeq 0.007$, we obtain for example $\frac{\dot{m}_{0}}{\dot{m}_{\text {fuel }}}=\mathrm{AFR} \cdot \omega_{0} \simeq 0.102$.

\subsection{Water-Fuel Ratio}

The second water mass flow rate involved is the one we specifically inject into the engine during WI process, noted $\dot{m}_{\text {inj }}$. This rate is usually related to the consumed fuel one, thanks to the Water-Fuel Ratio, noted WFR:

$$
\mathrm{WFR}=\frac{\dot{m}_{\mathrm{inj}}}{\dot{m}_{\mathrm{fuel}}}
$$

Depending on the concerned engine and of the WI purpose (performance increase or pollution mitigation), the Water-Fuel Ratio can be typically adjusted such as $0.2 \leq$ $\mathrm{WFR} \leq 1.5$ for usual liquid fuels [14, 27, 31-33], so values clearly larger than the ones related to the ambient humidity. For gaseous fuels, the values of WFR are usually larger, reaching sometimes $\mathrm{WFR} \simeq 3$ for natural gas fed spark ignited engines [35] and WFR $\simeq 9$ for hydrogen ones [34]. 
Table 1: Main properties of some current fuels consumed in internal combustion engines. Octane and Cetane are the reference fuels for spark ignited and compression ignited engines, respectively [29]. Properties of the E10 blend are obtained thanks to calculations detailed in Appendix A.1 page 6.

\begin{tabular}{lccccrc}
\hline Fuel & $\mathrm{x}$ & $\mathrm{y}$ & $\mathrm{z}$ & $M_{\text {fuel }}[\mathrm{g} / \mathrm{mol}]$ & $\mathrm{AFR}_{\text {st }}$ & $\beta$ \\
\hline Hydrogen $\left(\mathrm{H}_{2}\right)$ & 0 & 2 & 0 & 2.016 & 34.06 & 8.936 \\
Natural gas $\left(\sim \mathrm{CH}_{4}\right)$ & 1 & 4 & 0 & 16.04 & 17.12 & 2.246 \\
Ethanol $\left(\mathrm{C}_{2} \mathrm{H}_{5} \mathrm{OH}\right)$ & 2 & 6 & 1 & 46.07 & 8.94 & 1.173 \\
E10 & 6.8 & 13.2 & 0.2 & 98.22 & 13.99 & 1.211 \\
Usual gasoline $\left(\sim \mathrm{C}_{8} \mathrm{H}_{15}\right)$ & 8 & 15 & 0 & 111.20 & 14.51 & 1.215 \\
Octane $\left(\mathrm{C}_{8} \mathrm{H}_{18}\right)$ & 8 & 18 & 0 & 114.23 & 15.03 & 1.419 \\
Usual Diesel fuel $\left(\sim \mathrm{C}_{13.2} \mathrm{H}_{24.4}\right)$ & 13.2 & 24.4 & 0 & 183.14 & 14.47 & 1.200 \\
Cetane $\left(\mathrm{C}_{16} \mathrm{H}_{34}\right)$ & 16 & 34 & 0 & 226.44 & 14.86 & 1.352 \\
\hline
\end{tabular}

\subsection{Water produced by the combustion process}

Some water is also produced by the combustion process itself, with a resulting mass flow rate henceforth noted $\dot{m}_{\text {comb }}$. The combustion process taken into account is the complete one of an (oxygenated) hydrocarbon fuel of composition $\mathrm{C}_{x} \mathrm{H}_{y} \mathrm{O}_{z}$, with air. Complete means that the possible production of more complex and often hazardous components such as unburnt hydrocarbons, carbon monoxide and nitrogen oxides (see \$2.2), are not considered, neither the potential involvement of water in another chemical reaction.

The molar balance of such a combustion process can be described by the follow equation:

$$
\begin{gathered}
\mathrm{C}_{\mathrm{x}} \mathrm{H}_{\mathrm{y}} \mathrm{O}_{\mathrm{z}}+\lambda \cdot \nu_{\text {air }} \cdot\left(\mathrm{O}_{2}+\alpha \cdot \mathrm{N}_{2}\right) \\
\rightarrow \mathrm{x} \cdot \mathrm{CO}_{2}+\frac{\mathrm{y}}{2} \cdot \mathrm{H}_{2} \mathrm{O}+\lambda \cdot \alpha \cdot \nu_{\text {air }} \cdot \mathrm{N}_{2} \\
\quad+\left[(\lambda-1) \cdot\left(\mathrm{x}+\frac{\mathrm{y}}{4}\right)-\lambda \cdot \frac{\mathrm{z}}{2}\right] \cdot \mathrm{O}_{2}
\end{gathered}
$$

$\nu_{\text {air }}$ is the air related stoichiometric coefficient, used to calculate the stoichiometric Air-Fuel Ratio value of equation (3), and whom expression is:

$$
\nu_{\text {air }}=x+\frac{y}{4}-\frac{z}{2}
$$

$\alpha$ is the nitrogen to oxygen molar fraction in dry air : $\alpha=x_{\mathrm{N}_{2} \text {,air }} / x_{\mathrm{O}_{2} \text {,air }}=0.79 / 0.21 \simeq 3.76$. The respective numbers of carbon, hydrogen and oxygen atoms in balance (6), so x, y and $z$, are presented for some usual fuels in Table 1. From equation (6), it is easy to notice that the amount of water produced by such a combustion process is solely related to the hydrogen content of the consumed fuel, represented by the number y.

Considering any given equation similar to (6), we can relate the molar flow rate $\dot{n}_{j}$ of any product $j$ to the one any reactant $i$ by:

$$
\dot{n}_{j}=\frac{\nu_{j}}{\nu_{i}} \cdot \dot{n}_{i}
$$

Both molar flow rates are here counted as positive. When applied to fuel and water in Equation (6), this relation gives:

$$
\dot{n}_{\mathrm{comb}}=\frac{\nu_{\mathrm{H}_{2} \mathrm{O}}}{\nu_{\text {fuel }}} \cdot \dot{n}_{\text {fuel }}=\frac{\mathrm{y}}{2} \cdot \dot{n}_{\text {fuel }}
$$

The same relation, but expressed in mass, involves the fuel and water respective molar masses, and gives:

$$
\dot{m}_{\text {comb }}=\frac{\mathrm{y}}{2} \cdot \frac{M_{\mathrm{H}_{2} \mathrm{O}}}{M_{\text {fuel }}} \cdot \dot{m}_{\text {fuel }}=\beta \cdot \dot{m}_{\text {fuel }}
$$

$\beta$ is then the amount water produced, through the combustion reaction, by each unit of mass of the consumed fuel. Values of $\beta$ for previously mentioned fuels are presented in Table 1 as well. We can notice that the lower value of $\beta$, that corresponds to neat ethanol, is already within the highest part of the range of Water-Fuel Ratio, which is an optimistic indicator for the rest.

\subsection{Water extraction from exhaust gas stream}

If water is not supposed to be involved in any other chemical reaction than (6), the vapour mass flow rate contained in the exhaust gases one can be expressed, according to previous relations (1), (5) and (10), as:

$$
\begin{aligned}
\dot{m}_{\mathrm{exh}} & =\dot{m}_{0}+\dot{m}_{\mathrm{inj}}+\dot{m}_{\mathrm{comb}} \\
& =\dot{m}_{\mathrm{fuel}} \cdot\left(\mathrm{AFR} \cdot \omega_{0}+\mathrm{WFR}+\beta\right)
\end{aligned}
$$

In the rest, only a fraction $\varepsilon$ of this water vapour flow rate is supposed to be liquefied and recycled, as presented in Figure 1. This rate, henceforth noted $\dot{m}_{\text {recy }}$, is:

$$
\dot{m}_{\text {recy }}=\varepsilon \cdot \dot{m}_{\text {exh }}
$$

$\varepsilon$ is then also the effectiveness of the water recycling system used to get back water from the exhaust stream.

According to Moses-Debusk et al. [36] for instance, the use of already existing inorganic tubular membranes can lead to an effectiveness of such a water recycling process such as :

$$
50 \% \leq \varepsilon \leq 70 \%
$$

We will consider the same range of values for $\varepsilon$ in the rest.

\subsection{Water injection self supplying coefficient}

Let us now consider the possibility to supply the WI system with the sole recycled water flow rate coming back from the exhaust stream. For so, we can consider for example the follow parameter, called Exhaust Water Recirculation (EWR) self supplying coefficient :

$$
\psi=\frac{\dot{m}_{\mathrm{recy}}}{\dot{m}_{\mathrm{inj}}}
$$




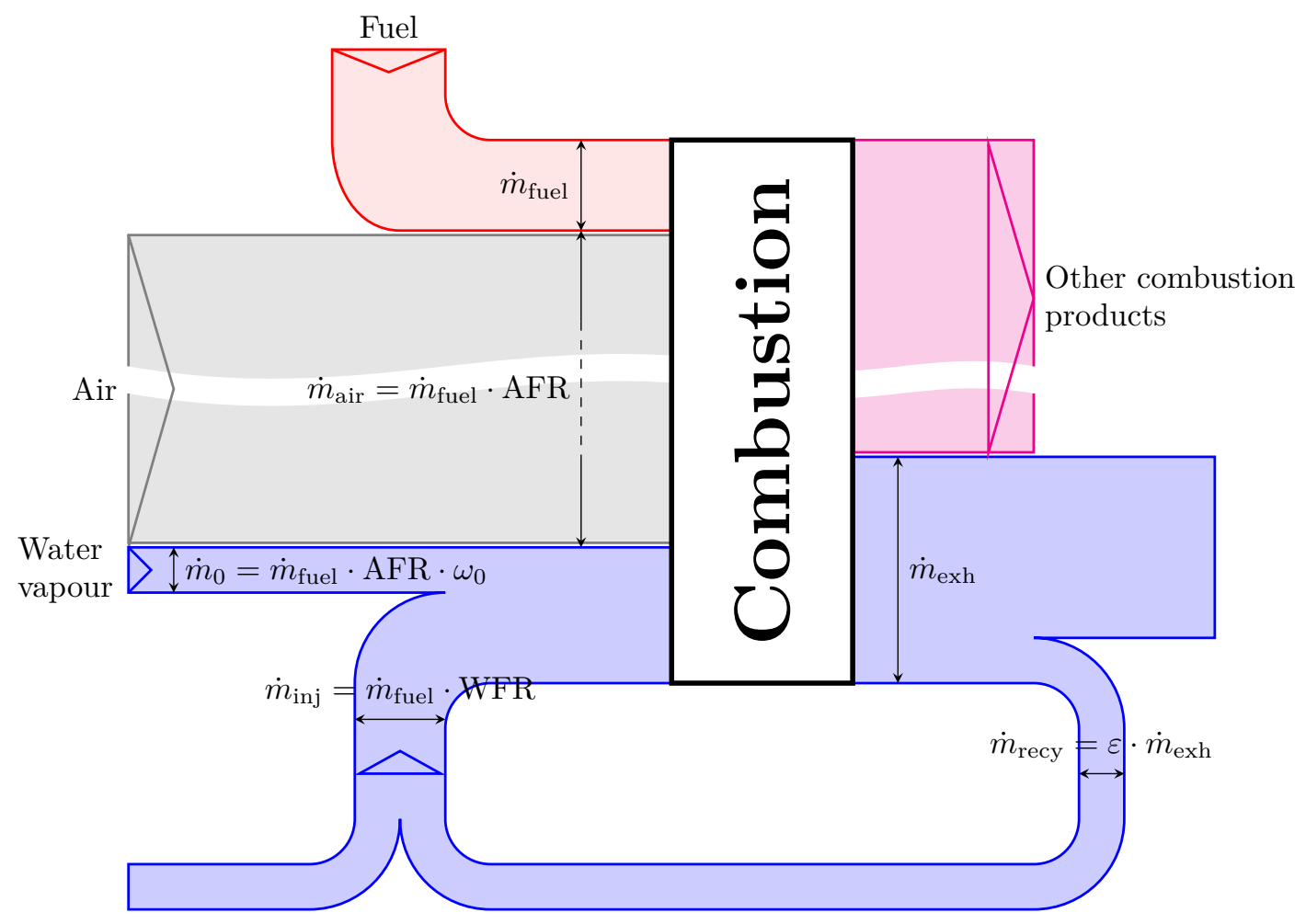

Figure 1: Representation of the flow rates exchanged by an ICE equipped with a WI system. Here the Exhaust Water Recirculation system is such as $\psi=\dot{m}_{\text {recy }} / \dot{m}_{\mathrm{inj}}<1$, and some water has to be consumed from the water tank (not drawn to scale).

The WI process can then be supplied by the sole EWR if $\psi=1$, whereas a supplementary tank is required if $\psi<1$. Combining equations (5), (11) and (12), we can express $\psi$ in another way:

$$
\psi=\varepsilon \cdot\left(1+\frac{\mathrm{AFR} \cdot \omega_{0}+\beta}{\mathrm{WFR}}\right)
$$

The ability of the EWR system to properly supply the WI process is then logically favoured, for a given fuel, by high values of the recycling effectiveness $\varepsilon$ and of the ambient specific humidity $\omega_{0}$, as well as by a low value of the required Water-Fuel Ratio. It is then possible to define a maximum value of the latter which ensures, for a given effectiveness $\varepsilon$, a self supplying operating mode of the whole system, corresponding to a value $\psi=1$ :

$$
\mathrm{WFR}_{\max }=\frac{\mathrm{AFR} \cdot \omega_{0}+\beta}{1 / \varepsilon-1}
$$

Let us consider now the application of previous relations on some practical example of WI use for vehicles.

\section{Results and discussion}

\subsection{Influence of ambient humidity}

Considering the positive role of the water vapour extract from the ambience, represented by the factor AFR $\cdot \omega_{0}$, on both values of $\psi$ and $\mathrm{WFR}_{\max }$ in equations (15) and (16), we will consider in the rest only a pessimistic value of the former, corresponding to cold and relatively dry weather situations. Hence, for a cold air with a temperature of $0^{\circ} \mathrm{C}$ and a relative humidity of $50 \%$, we have a minimum ambient specific humidity $\omega_{0} \simeq 1.89 \cdot 10^{-3}$, [30, chapter 6$]$. Any other situation, with a larger value of $\omega_{0}$, would make things better for the WI process.

\subsection{Usual liquid fuels}

Values of the maximum Water-Fuel Ratio $\mathrm{WFR}_{\max }$ of equation (16), for recycling effectivenesses given by (13), and stoichiometric combustion of three usual liquid fuels, are presented in Table 2 . In the same table are also presented the required values of the effectiveness $\varepsilon$ that make the system able to be self supplied for two extreme values of WFR extract from literature [14, 27, 31-33]. The same results are summarised in Figure 2. All these results are clearly in favour of the use of EWR for supplying WI processes in concerned engines. Even the most reasonable values of recycling effectiveness $(\varepsilon=50 \%)$ makes possible the supply of Water-Fuel Ratio located within the highest part of the usual range of values. Furthermore, the difference between gasoline and Diesel fuel is insignificant and suggests that the same apparatus would be setup indifferently on spark ignited and compression ignited engines propelled vehicles.

\subsection{Gaseous fuels}

The situation is also favourable to gas fed engines, by hydrogen $\left(\mathrm{H}_{2}\right)$ or by natural gas (represented here the methane $\mathrm{CH}_{4}$ ), mainly because of the higher hydrogen contents of such fuels (see the values of $\beta$ in Table 1 ), 
Table 2: Values of the maximum Water-Fuel Ratio of equation (16) for two typical values of the water vapour recycling efficiency $\varepsilon$, and of $\varepsilon$ of equation (15) corresponding to the minimum and maximum values of WFR found in the literature.

\begin{tabular}{lcccll}
\hline & \multicolumn{3}{c}{ WFR $_{\max }$} & \multicolumn{2}{c}{$\varepsilon$} \\
Fuel & $\lambda$ & $\varepsilon=50 \%$ & $\varepsilon=70 \%$ & WFR $=0.2$ & WFR $=1.5$ \\
\hline Gasoline & 1 & 1.242 & 2.899 & $13.9 \%$ & $54.7 \%$ \\
E10 & 1 & 1.237 & 2.864 & $13.9 \%$ & $54.8 \%$ \\
Diesel fuel & 1 & 1.237 & 2.887 & $14.0 \%$ & $55.0 \%$ \\
\hline & & & & WFR $=3$ & WFR $=9$ \\
Hydrogen & 2 & 9.064 & 21.150 & & $49.8 \%$ \\
Natural gas & 2 & 2.310 & 5.391 & $56.5 \%$ & \\
\hline
\end{tabular}

but also because of the larger amount of air needed for their proper combustion, that aspirate more ambient humidity in the combustion process. The values of $\mathrm{WFR}_{\max }$ and $\varepsilon$ of equations (16) and (15) for lean combustions of hydrogen [37] and natural gas [38], so with $\lambda=2$, are presented in the lower part of Table 2. The optimal amount of injected water highlighted by some authors, of about 9 for hydrogen fed spark ignited engines by Subramanian, Mallikarjuna, and Ramesh [34] and of about 3 for natural gas ones by Arruga et al. [35], is still within the available range of effectiveness of current membranes.

The EWR strategy is then potentially relevant to be setup also on future hydrogen or natural fed ICE propelled vehicles.

\section{Conclusions}

Liquid water injection into internal combustion engines is a well-known strategy of both performance improvement and pollution mitigation. However, when applied to ac- tual vehicles, the question quickly arises of the origin of the water needed for so. Do we have to carry on board a supplementary water tank? Of how much size?

To avoid as far as possible such a supplementary constraint, and its resulting costs, the principle of recycling the water vapour contained within exhaust gases has been considered for a while, and has been the goal of several patents $^{1}$. However, as far as we know, no global assessment of such strategy has be led to date.

Such an assessment is proposed in the current paper, with an analysis of the potential impacts of the fuel chemical composition, of the ambient humidity and of the actual Water-Fuel Ratio required by the water injection process. Considering the water recycling effectivenesses of existing membranes, already used for such a purpose, as long as the most pessimistic situations regarding to ambient humidity, we conclude that the Exhaust Water Recirculation (EWR) is a very promising solution, applicable to both liquid and gaseous fuels. Even the lowest values of this recycling effectiveness are compatible with the values

\footnotetext{
${ }^{1}$ Incidentally, the same idea is practically used for a while in fuel cells, the water produced in the heart of such systems being recycled and used to humidify the air absorbed by the intake [39].
}

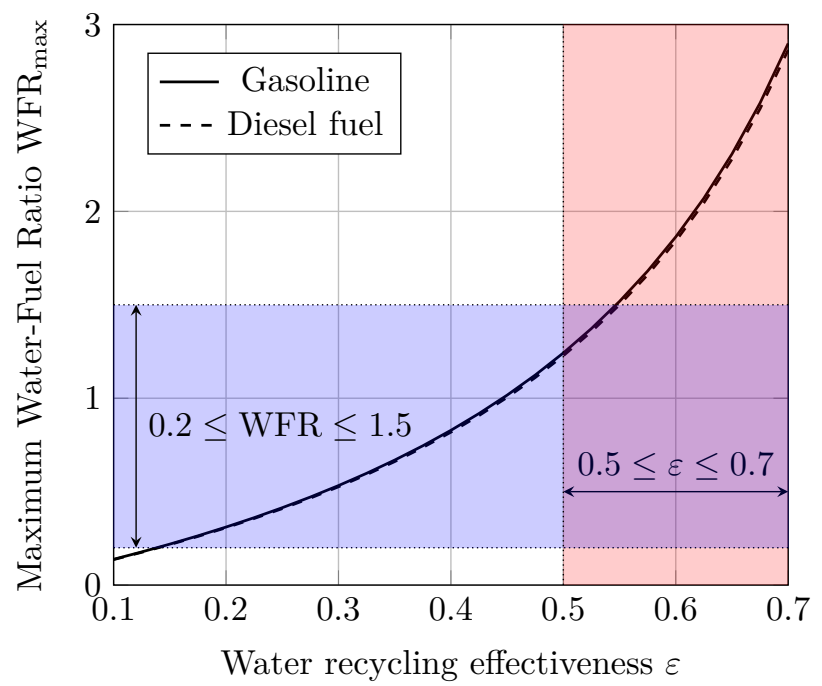

Figure 2: Evolution of the maximum Water-Fuel Ratio WFR max of equation (16) vs. the water recycling effectiveness $\varepsilon$, for stoichiometric combustions of gasoline and usual Diesel fuel. Ambient specific humidity is here $\omega_{0} \leq 0.002$. 
of Water-Fuel Ratio commonly found to be effective for such engines.

The results presented in this paper are probably not advanced enough to draw any definitive conclusion, but they are clearly encouraging and we hope they will encourage scientists and engineers involved in this topic to lead some related experiment, and hopefully to give further credibility to such an idea.

Acknowledgement The author would like to acknowledge the support of the PUCP Energy Laboratory for this research.

Declaration of conflicting interests The author declared no potential conflicts of interest with respect to the research, authorship, and/or publication of this article.

Funding The author received no financial support for the research, authorship, and/or publication of this article.

\section{A. Appendix}

\section{A.1. Ethanol-gasoline blend fuels}

\section{A.1.1. Chemical composition}

Lets us consider an ethanol-gasoline blend fuel called "EX" with $X$ the ethanol concentration in volume, as e.g. for the famous E10 commonly available in Europe and in the USA. If $\rho_{\text {eth }}$ and $\rho_{\text {gas }}$ are the respective densities of ethanol and gasoline, the blend one noted $\rho_{\mathrm{E} X}$ is given by:

$$
\rho_{\mathrm{E} X}=X \cdot \rho_{\mathrm{eth}}+(1-X) \cdot \rho_{\text {gas }}
$$

And the corresponding mass fraction of ethanol (noted here with the letter $w$ ) is:

$$
w_{\mathrm{eth}}=\frac{m_{\mathrm{eth}}}{m_{\mathrm{eth}}+m_{\mathrm{gas}}}=\left(1+\frac{1-X}{X} \cdot \frac{\rho_{\mathrm{gas}}}{\rho_{\mathrm{eth}}}\right)^{-1}
$$

Introducing the molar masses of these components, we can express the one of the blend as:

$$
M_{\mathrm{E} X}=\frac{m_{X}}{n_{X}}=\left(\frac{w_{\text {eth }}}{M_{\text {eth }}}+\frac{1-w_{\text {eth }}}{M_{\text {gas }}}\right)^{-1}
$$

The corresponding molar fraction of ethanol is then:

$$
x_{\mathrm{eth}}=w_{\mathrm{eth}} \cdot \frac{M_{\mathrm{EX}}}{M_{\mathrm{eth}}}
$$

From that, the equivalent contents of carbon, hydrogen and oxygen of each mole of the blend, so the $x, y$ and $z$ variables previously introduced, can be calculated thanks to:

$$
\begin{aligned}
& \mathrm{x}_{\mathrm{E} X}=x_{\text {eth }} \cdot \mathrm{x}_{\text {eth }}+\left(1-x_{\text {eth }}\right) \cdot \mathrm{x}_{\text {gas }} \\
& \mathrm{y}_{\mathrm{E} X}=x_{\text {eth }} \cdot \mathrm{y}_{\text {eth }}+\left(1-x_{\text {eth }}\right) \cdot \mathrm{y}_{\text {gas }} \\
& \mathrm{z}_{\mathrm{E} X}=x_{\text {eth }} \cdot \mathrm{z}_{\text {eth }}+\left(1-x_{\text {eth }}\right) \cdot \mathrm{z}_{\text {gas }}
\end{aligned}
$$

As presented in Table 1, we have for ethanol the values $\mathrm{x}_{\text {eth }}=2, \mathrm{y}_{\text {eth }}=6$ and $\mathrm{z}_{\text {eth }}=1$.

\section{A.1.2. Application to the E10 blend}

Considering the practical case of the usual E10 blend, considering $\rho_{\text {gas }} \simeq 789 \mathrm{~kg} / \mathrm{m}^{3}$ and $\rho_{\text {eth }} \simeq 732 \mathrm{~kg} / \mathrm{m}^{3}$, we obtain thanks to (17), a blend density $\rho_{\mathrm{E} 10} \simeq 783 \mathrm{~kg} / \mathrm{m}^{3}$. According to (18), we have the respective mass fractions of both components $w_{\text {eth }} \simeq 9.35 \%$ and $w_{\text {gas }} \simeq 90.65 \%$. Based on the molar masses $M_{\text {eth }}=46.07 \mathrm{~g} / \mathrm{mol}$ and $M_{\text {gas }}=111.20 \mathrm{~g} / \mathrm{mol}$ and on relation (19), the molar mass of the blend is thus $M_{\mathrm{E} 10} \simeq 98.22 \mathrm{~g} / \mathrm{mol}$. Using (20), we obtain $x_{\text {eth }} \simeq 19.65 \%$ and $x_{\text {gas }} \simeq 80.35 \%$. Carbon, hydrogen and oxygen contents of the blend are then $\mathrm{x}_{\mathrm{E} 10} \simeq 6.8$, $\mathrm{y}_{\mathrm{E} 10} \simeq 13.2$ and $\mathrm{z}_{\mathrm{E} 10} \simeq 0.2$, and so the equivalent chemical composition $\mathrm{C}_{6.8} \mathrm{H}_{13.2} \mathrm{O}_{0.2}$ presented in Table 1.

\section{Nomenclature}

$\begin{array}{ll} & \text { Notations } \\ m & \text { Mass, }[\mathrm{kg}] \\ \dot{m} & \text { Mass flow rate, }[\mathrm{kg} / \mathrm{s}] \\ M & \text { Molar mass, }[\mathrm{kg} / \mathrm{mol}] \\ \dot{n} & \text { Molar flow rate, }[\mathrm{mol} / \mathrm{s}] \\ T & \text { Temperature, }\left[{ }^{\circ} \mathrm{C}\right] \\ w & \text { Mass fraction } \\ x & \text { Molar fraction } \\ \mathrm{x} & \text { Carbon content of fuel } \\ X & \text { Volumetric fraction } \\ \mathrm{y} & \text { Hydrogen content of fuel } \\ \mathrm{z} & \text { Oxygen content of fuel } \\ & \text { Greek symbols }\end{array}$

Nitrogen to oxygen molar fraction in dry air

$\beta \quad$ Amount of water produced through combustion reaction for each unit of fuel consumed

$\varepsilon \quad$ Effectiveness of the water recycling system

$\lambda \quad$ Air-Fuel equivalence Ratio

$\nu \quad$ Stoichiometric coefficient

$\omega \quad$ Specific humidity

$\psi \quad$ Exhaust water recirculation self supplying coefficient

$\rho$ Density, $\left[\mathrm{kg} / \mathrm{m}^{3}\right]$

\section{Subscripts}

$0 \quad$ Surroundings

air Dry air

comb Water produced by combustion

eth Ethanol

exh Exhaust gases

fuel Fuel consumed

gas Gasoline

inj Water injection into the engine

liq Liquid water

recy Exhaust recycled water

st Stoichiometric proportions

vap Water vapour

\section{Acronyms}

AFR Air-Fuel Ratio

CI Compression Ignited engines

DWI Direct Water Injection

EWR Exhaust Water Recirculation

ICE Internal Combustion Engines

IWI Indirect Water Injection

SI Spark Ignited engines 
WFR Water-Fuel Ratio

WI Water Injection

\section{References}

[1] J. Berkeley. "The death of the internal combustion engine". In: The Economist (Aug. 2017). URL: https : / / www . economist . com / news / leaders / 21726071 - it - had - good - run - end - sight machine-changed-world-death.

[2] V. Smil. Energy Myths and Realities: Bringing Science to the Energy Policy Debate. AEI Press, 2010.

[3] G. J. Offer et al. "Comparative analysis of battery electric, hydrogen fuel cell and hybrid vehicles in a future sustainable road transport system". In: Energy Policy 38.1 (2010), pp. 24-29. DOI: $10.1016 /$ j.enpol.2009.08.040.

[4] L. P. Fernandez et al. "Assessment of the impact of plug-in electric vehicles on distribution networks". In: IEEE Transactions on Power Systems 26.1 (2011), pp. 206-213. DOI: 10 . 1109 / TPWRS . 2010.2049133 .

[5] P. Hugon. Improvement in Gas-Engines. United States Patent 49346. 1865. URL: https : / / www . google.fr/patents/US49346.

[6] M. R. Rowe and G. T. Ladd. "Water Injection for Aircraft Engines". In: SAE Technical Paper 460192 (1946). DOI: $10.4271 / 460192$.

[7] Sam Sheehan. BMW M4 GTS's water injection system to feature on other cars from 2019. 2016. URL: https : / / www . autocar . co . uk / car-news / industry / bmw - m4 - gtss - water - injection system-feature-other-cars-2019.

[8] R. Smith. Alpine \& Renault: The Development of the Revolutionary Turbo F1 Car, 1968 to 1979. Veloce Publishing Ltd, 2008.

[9] J. E. Lindberg. Engine combustion control system and method employing condensation of some exhaust gas. United States Patent US4503813 A. 1983. URL: https://www . google.fr/patents/US4503813.

[10] C. C. Andrews et al. Water sources for automotive devices. United States Patent US6804949 B2. 2004. URL: https : / / www . google . fr / patents / US6804949.

[11] M. Snow. Water injection system using water reclaimed from combustion exhaust. United States Patent US8820270 B2. 2013. URL: https : / / www . google.fr/patents/US8820270.

[12] X. Tauzia, A. Maiboom, and S. Rahman Shah. "Experimental study of inlet manifold water injection on combustion and emissions of an automotive direct injection Diesel engine". In: Energy 35.9 (2010), pp. 3628-3639. DOI: $10.1016 / \mathrm{j}$. energy . 2010.05 . 007.
[13] A. Boretti. "Water injection in directly injected turbocharged spark ignition engines". In: Applied Thermal Engineering 52.1 (2013), pp. 62-68. DOI: 10 . 1016/j . applthermaleng. 2012.11.016.

[14] F. Hoppe et al. "Water injection for gasoline engines: Potentials, challenges, and solutions". In: International Journal of Engine Research 17.1 (2016), pp. 86-96. DOI: $10.1177 / 1468087415599867$.

[15] A. Vaudrey. "Thermodynamics of indirect water injection in internal combustion engines: theoretical assessment of the fresh mixture cooling effect". In: engrXiv Preprints (2017). DOI: 10.17605/OSF. IO/ SFKR8.

[16] A. Mohan et al. "Thermo-fluid dynamic analysis of wet compression process". In: Journal of Mechanical Science and Technology 30.12 (2016), pp. 5473-5483. DOI: $10.1007 / \mathrm{s} 12206-016-1115-4$.

[17] R. J. Brun, H. Lowell Olsen, and C. D. Miller. End Zone Water Injection as a means of suppressing knock in a Spark-Ignition Engine. Tech. rep. Aircraft Engine Research Laboratory, Cleveland, Ohio: National Advisory Committee for Aeronautics, Report No. E4I27, 1944. 15 pp.

[18] P. Lappas. "Burn-rate and knock reduction in the spark ignition engine". In: International Journal of Energy Research 20.9 (1996), pp. 829-838. DOI: 10 . 1002/ (SICI) 1099-114X (199609) 20 : 9<829 : : AIDER203>3.0. CO;2-L.

[19] R.-H. Chen et al. "Gasoline displacement and NOx reduction in an SI engine by aqueous alcohol injection". In: Fuel 89 (2010), pp. 604-610. DOI: 10.1016/ j.fuel.2009.07.015.

[20] J.-K. Wang et al. "Reduction of Nitric Oxide Emission from a SI Engine by Water Injection at the Intake Runner". In: ASME 2009 International Mechanical Engineering Congress and Exposition. Lake Buena Vista, Florida, USA, Nov. 2009, pp. 335-340. DOI: $10.1115 /$ IMECE2009-12517.

[21] B. Peters and R. Stebar. "Water-Gasoline FuelsTheir Effect on Spark Ignition Engine Emissions and Performance". In: SAE Technical Paper 760547 (1976). DOI: 10.4271/760547.

[22] J. Harrington. "Water Addition to GasolineEffect on Combustion, Emissions, Performance, and Knock". In: SAE Technical Paper 820314 (1982). DOI: $10.4271 / 820314$.

[23] K. Tsao, C. Wang, and E. Miller. "Performance of Gasoline-Water Fuel in a Modified SI Engine". In: SAE Technical Paper 841399 (1984). DOI: 10.4271/ 841399.

[24] S. Brusca and R. Lanzafame. "Water Injection in IC - SI Engines to Control Detonation and to Reduce Pollutant Emissions". In: SAE Technical Paper 2003-01-1912 (2003). DOI: 10.4271/2003-01-1912.

[25] J. B. Heywood. Internal Combustion Engine Fundamentals. McGraw-Hill, 1988. 
[26] F. L. Dryer. "Water Addition to Practical Combustion Systems - Concepts and Applications". In: Proceedings of the Combustion Institute 16.1 (1977), pp. 279-295. DOI: 10.1016/S0082-0784(77)803329.

[27] J. Parley Wilson. "Effects of Water Injection and Increased Compression Ratio in a Gasoline Spark Ignition Engine". MSc Thesis. University of Idaho, 2011. URL: http : / / digital . lib. uidaho . edu / cdm/ref/collection/IR/id/11.

[28] A. Sarvi, P. Kilpinen, and R. Zevenhoven. "Emissions from large-scale medium-speed diesel engines: 3. Influence of direct water injection and common rail". In: Fuel Processing Technology 90 (2009), pp. 222-231. DOI: $10.1016 /$ j .fuproc . 2008. 09 . 003.

[29] B. Challen and R. Baranescu. Diesel Engine Reference Book. Butterworth-Heinemann, 1999.

[30] ASHRAE Handbook: Fundamentals. American Society of Heating, Refrigerating and Air-Conditioning Engineers, 2001.

[31] F. Bedford et al. "Effects of Direct Water Injection on DI Diesel Engine Combustion". In: SAE Technical Paper 2000-01-2938 (2000). DOI: 10.4271/200001-2938.

[32] J. Kim et al. "Effects of water direct injection on the torque enhancement and fuel consumption reduction of a gasoline engine under high-load conditions". In: International Journal of Engine Research 17.7 (2016), pp. 795-808. DOI: 10.1177 / 1468087415613221.

[33] R. Lanzafame. "Water Injection Effects In A SingleCylinder CFR Engine". In: SAE Technical Paper 1999-01-0568 (1999). DOI: 10.4271/1999-01-0568.
[34] V. Subramanian, J. M. Mallikarjuna, and A. Ramesh. "Effect of water injection and spark timing on the nitric oxide emission and combustion parameters of a hydrogen fuelled spark ignition engine". In: International Journal of Hydrogen Energy 32 (2007), pp. 1159-1173. DOI: 10 . 1016/j . i jhydene. 2006 . 07.022 .

[35] H. Arruga et al. "Effect of intake manifold water injection on a natural gas spark ignition engine: an experimental study". In: IOP Conf. Series: Materials Science and Engineering 257 (2017), p. 012029. DOI: $10.1088 / 1757-899 X / 257 / 1 / 012029$.

[36] M. Moses-Debusk et al. "Ceramics for Environmental and Energy Applications II". In: Wiley, 2014. Chap. 16: Understanding the Effect of Dynamic Feed Conditions on Water Recovery from IC Engine Exhaust by Capillary Condensation with Inorganic Membranes, pp. 143-151. DOI: 10 . $1002 /$ $9781118771327 . \operatorname{ch} 16$.

[37] S. Verhelst and T. Wallner. "Hydrogen-fueled internal combustion engines". In: Progress in Energy and Combustion Science 35 (2009), pp. 490-527. DOI: $10.1016 / j$. pecs . 2009.08.001.

[38] T. Korakianitis, A. M. Namasivayam, and R. J. Crookes. "Natural-gas fueled spark-ignition (SI) and compression-ignition (CI) engine performance and emissions". In: Progress in Energy and Combustion Science 37 (2011), pp. 89-112. DOI: $10.1016 / \mathrm{j}$. pecs.2010.04.002.

[39] V. Réguillet et al. "Definition of efficiency criteria for a fuel cell humidifier: application to a low power proton exchange membrane fuel cell system for negative surrounding temperatures". In: Applied Thermal Engineering 58.1-2 (2013), pp. 382-393. DOI: 10.1016/j . applthermaleng.2013.03.055. 